\title{
Ethnic Differences in Efficacy and Safety of Alogliptin: A Systematic Review and Meta-Analysis
}

Yuli Cai · Tianshu Zeng $\cdot$ Zhongyuan Wen · Lulu Chen

Received: October 2, 2017 / Published online: December 20, 2017

(c) The Author(s) 2017. This article is an open access publication

\begin{abstract}
Introduction: Alogliptin is a highly selective, potent, and orally available dipeptidyl peptidase-4 (DPP-4) inhibitor. This study compared the glucose-lowering efficacy and safety of alogliptin between Asian and non-Asian patients with type 2 diabetes.

Methods: We systematically searched MEDLINE, EMBASE, Cochrane Library, and ISI Web of Science databases for articles published June 2017 and earlier in English. We identified randomized controlled trials (RCTs) of adults with type 2 diabetes that compared alogliptin with placebo as either monotherapy or add-on therapy. We divided subgroups by ethnicity, and compared the results of alogliptin use in Asian and non-Asian-dominant studies.
\end{abstract}

Enhanced content To view enhanced content for this article go to http://www.medengine.com/Redeem/ 0CFCF0601D7EFA98.

Y. Cai $\cdot$ Z. Wen $(\bowtie)$

Department of Endocrinology, Renmin Hospital of

Wuhan University, 99 Zhangzhidong Road,

Wuhan 430060, China

e-mail: wenzywurm@163.com

T. Zeng · L. Chen $(\bowtie)$

Department of Endocrinology, Union Hospital, Tongji Medical College, Huazhong University of Science and Technology, 1277 Jiefang Road,

Wuhan 430022, China

e-mail: cheria_chen@126.com
Results: A total of 15 RCTs with 4456 patients with type 2 diabetes were included in this study. Alogliptin lowered glycated hemoglobin (HbA1c) to a much greater extent in Asiandominant studies [- 0.75\% $(95 \% \mathrm{CI}-0.84$ to $-0.65)]$ than in non-Asian-dominant studies $[-0.61 \%(95 \% \mathrm{CI}-0.68$ to -0.54$)](P=0.02)$. The risk ratio of achieving HbA1c goal was larger in Asian-dominant studies [2.88 (95\% CI 2.15-3.87)] than in non-Asian-dominant studies [1.93 (95\% CI 1.55-2.41)] $(P=0.03)$. The postprandial blood glucose-lowering efficacy was higher in Asian-dominant studies [- $2.42 \mathrm{mmol} / \mathrm{l}(95 \% \mathrm{CI}-2.99$ to -1.85$)]$ than in non-Asian-dominant studies $[-0.60 \mathrm{mmol} / \mathrm{l}$ (95\% CI -1.60 to 0.40$)$ ] $(P=0.002)$, while the fasting blood glucose and body weight changes were similar between the two subgroups. The incidence of adverse events, including hypoglycemia, nasopharyngitis, upper respiratory tract infection, headache, and diarrhea, were comparable between the two groups.

Conclusions: Alogliptin is more effective in improving glycemic levels in Asians than in other ethnic populations. Future studies are required to explore the potential mechanisms.

Keywords: Alogliptin; Asian; Meta-analysis; Type 2 diabetes 


\section{INTRODUCTION}

Type 2 diabetes mellitus (T2DM) is becoming a worldwide disease, especially, in Asia; it is expected that by 2025, 380 million Asian people will have type 2 diabetes [1]. Compared to other races, Asian patients with type 2 diabetes are physiologically characterized by lower $\beta$-cell function and less obesity [2]. The increase in prevalence of type 2 diabetes in the Asian population may be linked to the strong gene-environment interaction associated with lifestyle changes due by modernization [3].

To date, dipeptidyl peptidase-4 (DPP-4) inhibitors and glucagon-like peptide-1 (GLP-1) analogues are increasingly popular in clinical use. Interestingly, several meta-analyses compared the glycated hemoglobin (HbA1c)-lowering effect of DPP-4 inhibitors and GLP-1 analogues in Asian-dominant studies ( $\geq 50 \%$ Asian population) against those in non-Asiandominant studies ( $<50 \%$ Asian population) [4-6]. Both DPP-4 inhibitors and GLP-1 analogues include many different kinds of agents. For example, alogliptin, sitagliptin, and vildagliptin are DPP-4 inhibitors; liraglutide and exenatide are GLP-1 analogues. Actually, it is still not clear whether the glucose-lowering efficacy of any single incretin-based drug differs by ethnic groups. Thus, we carried out a systematic review and meta-analysis to explore the efficacy as well as safety of alogliptin in Asians and other ethnic populations.

\section{METHODS}

\section{Literature Search}

We systematically searched MEDLINE, EMBASE, Cochrane Library, and ISI Web of Science databases for articles published up until June 2017 in English. Relevant articles were identified using generic and brand names of "alogliptin" and "type 2 diabetes" as keyword search terms. We supplemented this search by a manual search of the reference list of relevant articles.

\section{Inclusion Criteria}

Inclusion criteria were as follows: (1) all subjects were non-pregnant adults with T2DM; (2) $\geq 12$ weeks' duration; (3) studies involved randomized controlled trials (RCTs); (4) methodologies compared alogliptin with placebo; (5) HbA1c levels were reported as one of the outcomes; and (6) in the case of duplicate publications, only the population with larger sample size or that containing more useful data was included. Exclusion criteria were trials enrolling patients (1) with type 1 diabetes; (2) health or pregnant; (3) with hepatic or renal impairment.

\section{Data Extraction}

We extracted data using the methods described in previous work [7]. The properties extracted from each selected article were as follows: (1) study characteristics, including first author name, year of publication, study design, and sample size; (2) participants' baseline characteristics, including age, sex, ethnicity, baseline HbA1c, and body weight; and (3) outcomes of efficacy in terms of change of HbA1c and body weight from baseline, and the proportion of patients achieving the glycemic goal; (4) safety outcomes, as derived from the percentage of participants experiencing adverse events in each group, such as hypoglycemic event, nasopharyngitis, or upper respiratory tract infection.

\section{Quality Assessment}

Study quality was assessed according to the Cochrane Collaboration's risk of bias tool [8], which is widely used to evaluate the quality of RCTs. The criteria were (1) random sequence generation, (2) allocation concealment, (3) blinding of participants and personnel, (4) incomplete outcome data, and (5) selective reporting. We evaluated each report for overall risk of bias of using these five criteria. Risk was deemed high if any domain presented high bias, low if all key domains (except random sequence 
generation and allocation concealment) were of low bias, and unclear in all other cases.

\section{Statistical Analysis}

Consistent with previous studies, we categorized the studies into Asian-dominant studies if the percentage of Asian participants was at least $50 \%$; otherwise, the study was deemed a nonAsian-dominant study. Statistical analyses were performed using the Cochrane Collaboration RevMan 5.2 (Copenhagen: The Nordic Cochrane Centre, The Cochrane Collaboration, 2012) and STATA 12.0 (Stata Corporation, College Station, TX, USA). For continuous data, weighted mean difference (WMD) and 95\% confidence interval (CI) were calculated to assess the difference between intervention group and control group. If a paper did not report a standard deviation, we calculated this according the sample size and standard error or 95\% CI. Dichotomous outcomes were expressed as risk ratios and $95 \%$ CI. $\chi^{2}$-test-based $Q$ statistic test and $I^{2}$ were used to assess heterogeneity among studies. If $P>0.05$ in $Q$ test or $I^{2}<50 \%$, the fixed effect model was selected [9], or else the random effect model was used [10].

\section{Compliance with Ethics Guidelines}

This article is based on previously conducted studies and does not involve any new studies of human or animal subjects performed by any of the authors.

\section{RESULTS}

\section{Search Results}

The search strategy retrieved 359 potentially relevant references. On the basis of the inclusion criteria, 15 RCTs [11-25] were included in the following meta-analysis and 344 papers were excluded. The selection process is shown in Fig. 1.

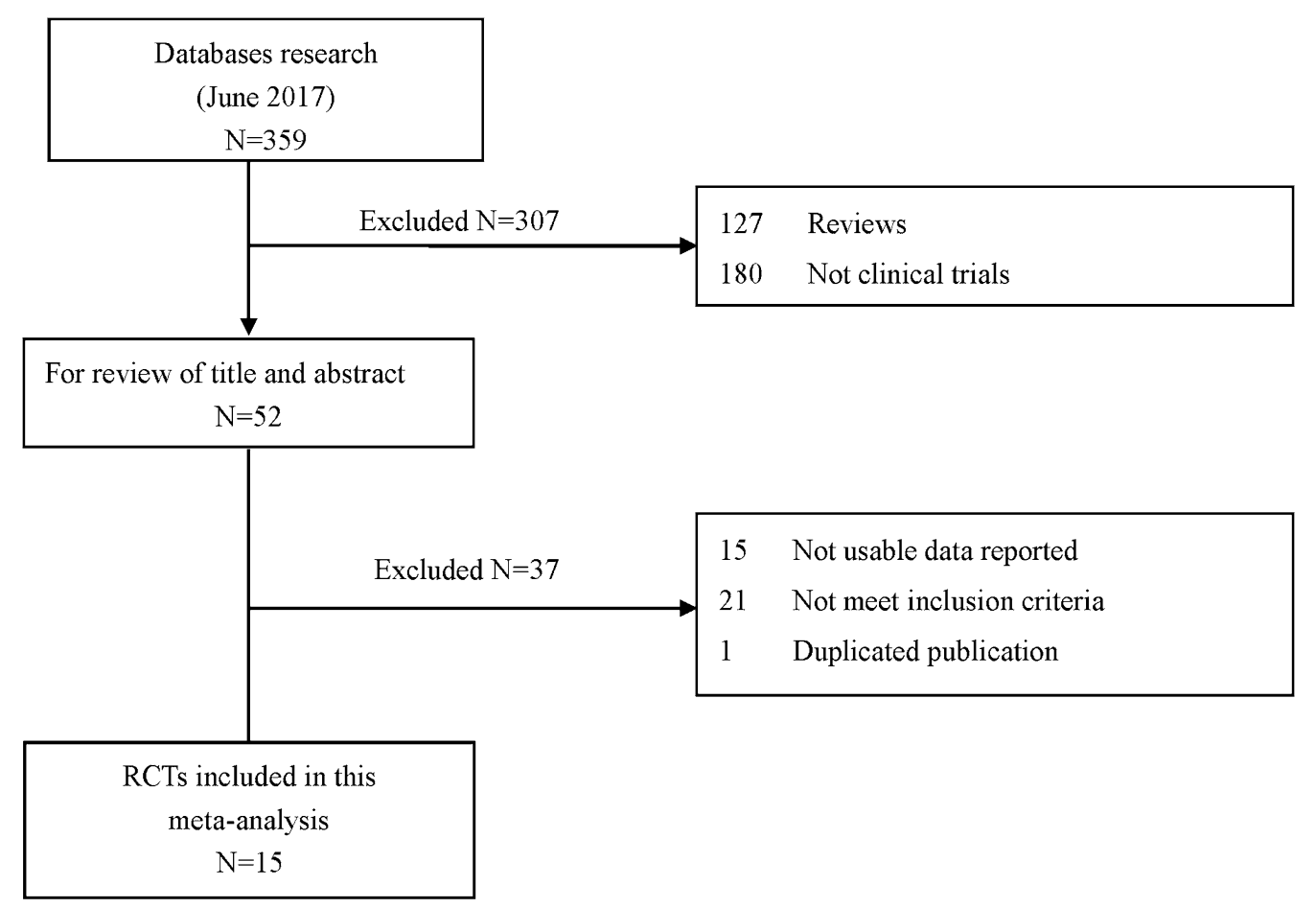

Fig. 1 Study flow diagram 


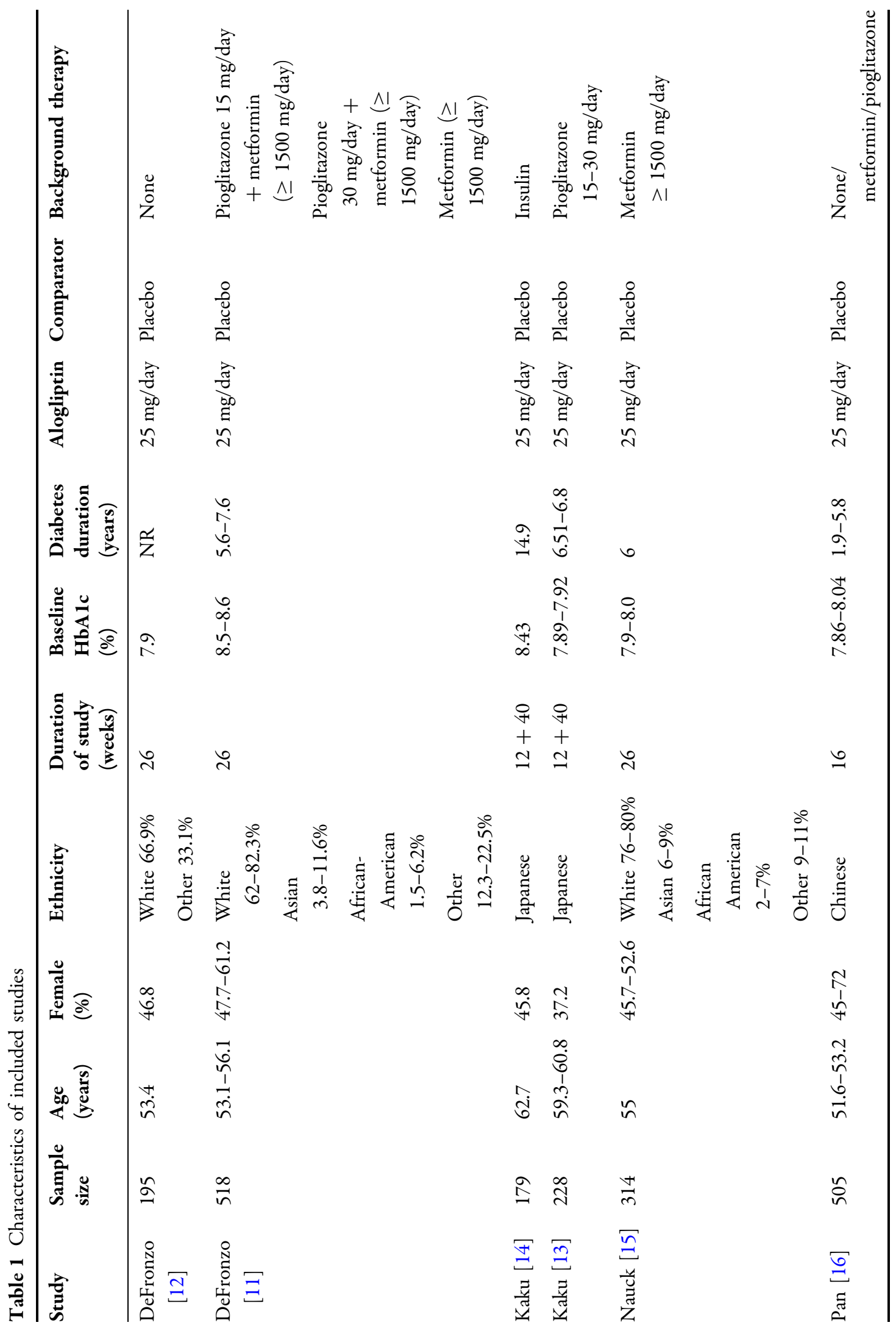




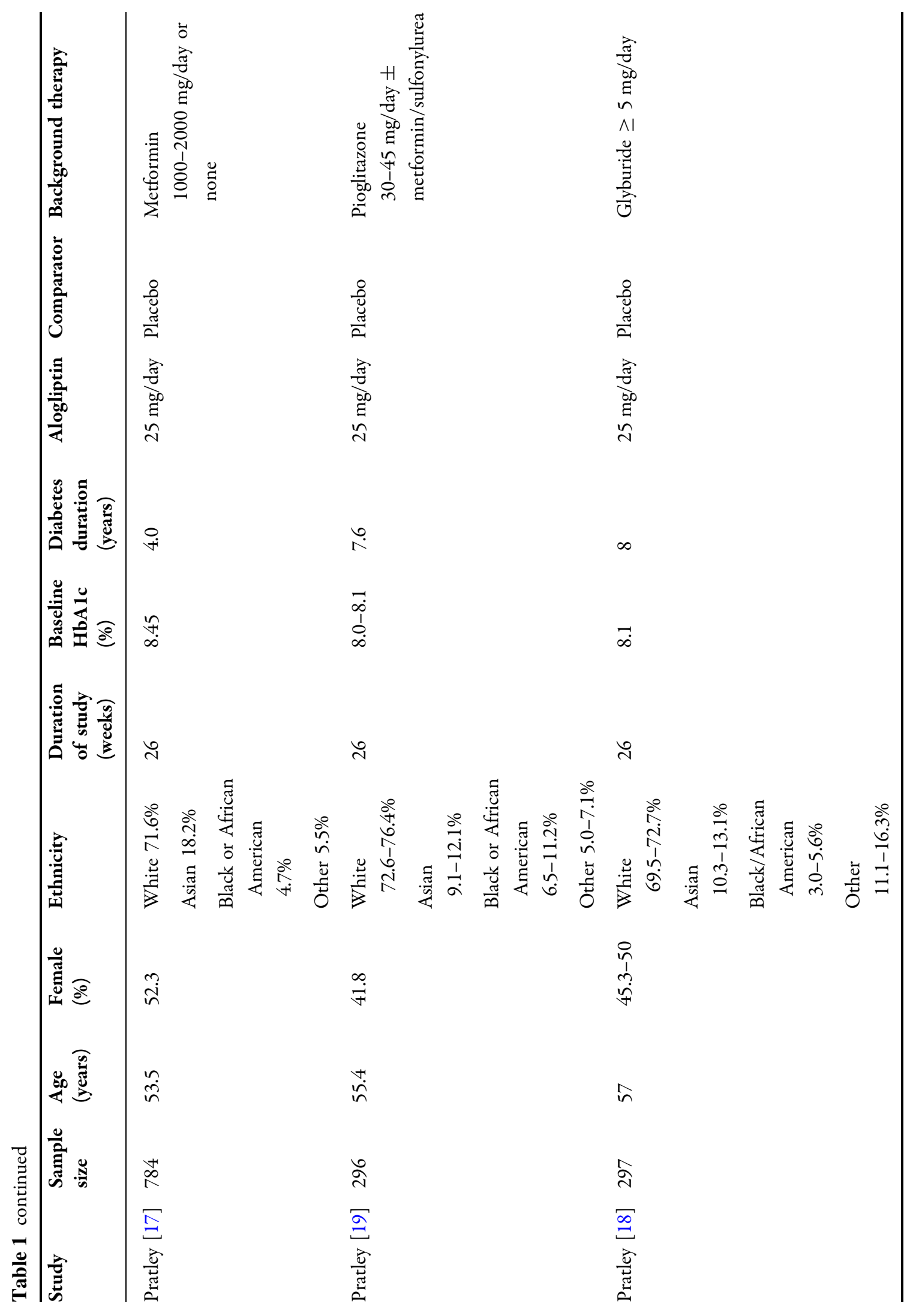




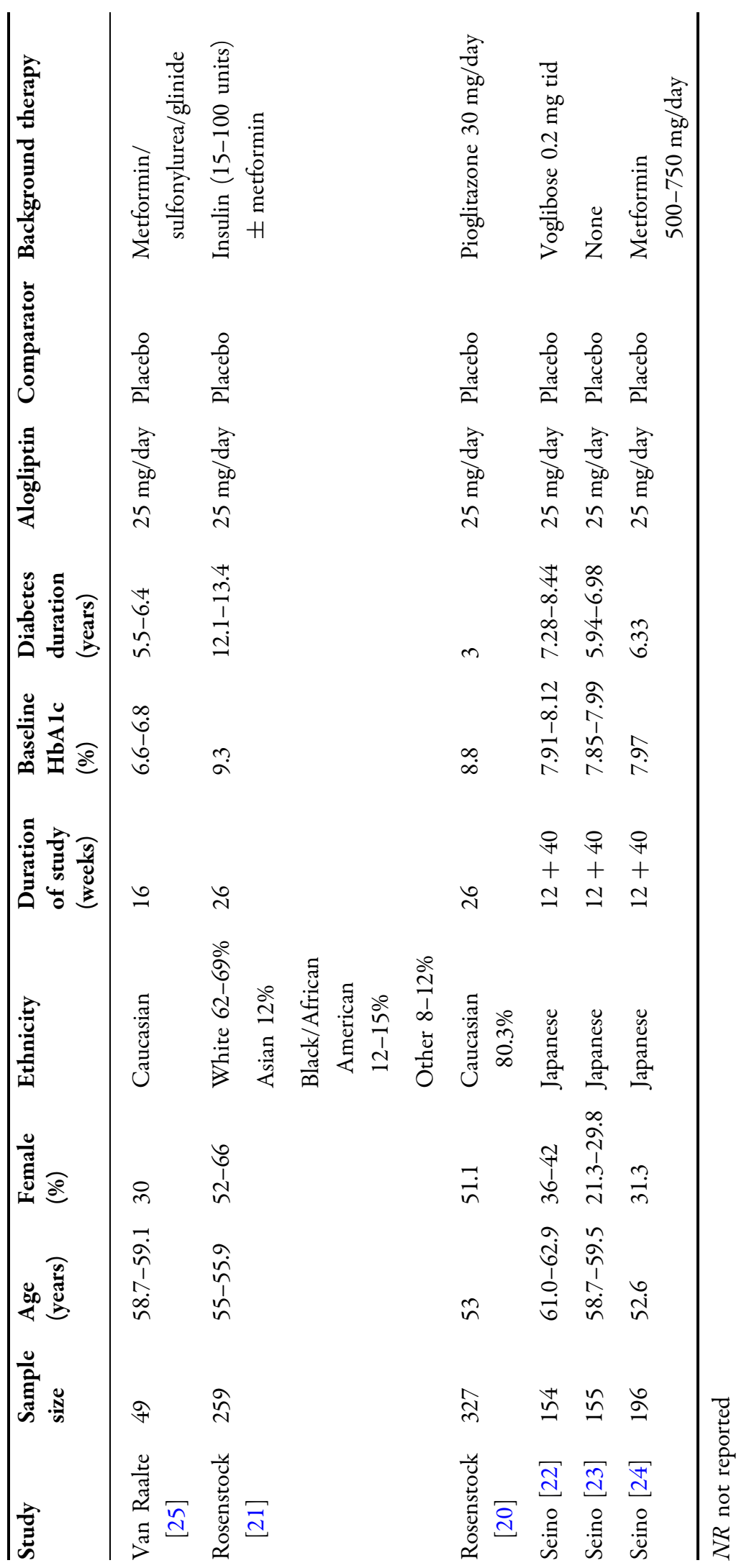




\section{Study and Patient Characteristics}

A total of 15 RCTs compared alogliptin with placebo as monotherapy or add-on therapy. Add-on therapy included metformin, pioglitazone, glipizide, voglibose, and insulin. All studies were multicenter trials, nine were international [11, 12, 15, 17-21, 25], five studies were conducted in Japan [13, 14, 22-24], and one study was carried out in China [16]. All trials used parallel study design with 2-12 arms; however, we excluded some arms of the included studies because several doses seemed unlikely to be used in clinical practice. In that way, we extracted only a dose of $25 \mathrm{mg}$ administered once daily. The studies under consideration were of 12-52 weeks' duration. We excluded the extensive study of four trials [13, 14, 22, 23], since the studies switched to open-label and had no control group in the extension. All RCTs were sponsored by Takeda Pharmaceutical Company.

A total of 4456 patients with T2DM were included in the present meta-analysis and systematic review. The mean age of the participants in the studies ranged from 51.6 to 69.9 years, female proportion ranged from $21.3 \%$ to $72 \%$, and the mean baseline HbA1c ranged from $6.6 \%$ to $9.3 \%$. Table 1 summarizes the main characteristics of included studies.

\section{Risk of Bias Within Studies}

According to the Cochrane Collaboration's risk of bias tool, overall risk of bias was judged for the primary outcomes was low in four $[13,16,22,23]$, unclear in ten $[11,12,14,15,17-21,24]$, and high in one report [25], mainly due to lack information on the random sequence generation. The average quality of the RCTs was acceptable (Table 2).

\section{HbA1c}

Figure 2a shows the meta-analysis of the change in HbA1c from baseline for the alogliptin in comparison with placebo. It can be seen that a total of 14 trials [11, 13-25] fulfilled inclusion criteria. Overall, the meta-analysis found that alogliptin resulted in lowering $\mathrm{HbA1c}$ much greater than the placebo $(\mathrm{WMD}=-0.68 \%, 95 \%$ CI -0.74 to $\left.-0.61, P<0.00001 ; I^{2}=57 \%\right)$. In the Asian-dominant studies, HbA1c changed by $-0.75 \%$ (95\% CI -0.84 to $\left.-0.65 ; I^{2}=59 \%\right)$. In the non-Asian studies, HbA1c decreased $-0.61 \%$ (95\% CI -0.68 to $\left.-0.54 ; I^{2}=19 \%\right)$. The difference between two subgroups was statistically significant $(P=0.02)$.

\section{Percentage of Patients Achieving HbA1c Target}

Twelve studies [12-20, 22-24] explored the proportion of participants achieving HbA1c targets. Seven trials [12, 15-20] determined $\mathrm{HbA} 1 \mathrm{c} \leq 7 \%$ as the treatment target according to the American Diabetes Association (ADA) [26], while five trials [13, 14, 22-24] performed in Japan set HbA1c $<6.9 \%$ as the goal based on the Japanese Diabetes Society and the European Association for the Diabetes [27]. As expected, the percentage of patients achieving HbA1c target was significantly larger with alogliptin [risk ratio $(\mathrm{RR})=2.38$, 95\% CI 1.96-2.91, $P<0.0001 ; \quad I^{2}=59 \%$ ] (Fig. 2b). The RR was numerically greater in the Asian-dominant studies than Non-Asian-dominant studies [2.88 $(95 \%$ CI $2.15-3.87)$ versus $1.93 \quad(95 \%$ CI 1.55-2.41), $P=0.03]$.

\section{Fasting Blood Glucose}

A total of 14 trials [11-23, 25] explored the fasting blood glucose (FBG) level changes after using alogliptin or placebo. Overall, FBG decreased more significantly in alogliptin group $(\mathrm{WMD}=-1.12 \mathrm{mmol} / \mathrm{l}, \quad 95 \% \mathrm{CI}-1.28$ to $\left.-0.97, P<0.00001 ; I^{2}=55 \%\right)$. There was no difference $(P=0.53)$ between Asian-dominant studies $[-1.07 \mathrm{mmol} / \mathrm{l} \quad(95 \%$ CI -1.28 to $\left.-0.85) ; \quad I^{2}=44 \%\right]$ and Non-Asian-dominant studies $[-1.16 \mathrm{mmol} / \mathrm{l} \quad(95 \% \quad \mathrm{CI}-1.37$ to -0.96 ); $I^{2}=47 \%$ ] (Fig. 2c).

\section{Postprandial Blood Glucose}

Only four trials $[13,17,23,24]$ explored postprandial blood glucose (PBG) level changes. The 
Table 2 Summary of risk of bias assessment

\begin{tabular}{|c|c|c|c|c|c|c|}
\hline Study ID & $\begin{array}{l}\text { Random } \\
\text { sequence } \\
\text { generation }\end{array}$ & $\begin{array}{l}\text { Allocation } \\
\text { concealment }\end{array}$ & $\begin{array}{l}\text { Blinding of } \\
\text { participants and } \\
\text { personnel }\end{array}$ & $\begin{array}{l}\text { Incomplete } \\
\text { outcome data }\end{array}$ & $\begin{array}{l}\text { Selective } \\
\text { reporting }\end{array}$ & $\begin{array}{l}\text { Overall } \\
\text { risk of bias }\end{array}$ \\
\hline $\begin{array}{c}\text { DeFronzo } \\
{[12]}\end{array}$ & $\mathrm{U}$ & $\mathrm{U}$ & $\mathrm{L}$ & $\mathrm{L}$ & $\mathrm{L}$ & $\mathrm{U}$ \\
\hline $\begin{array}{c}\text { DeFronzo } \\
{[11]}\end{array}$ & $\mathrm{U}$ & $\mathrm{U}$ & $\mathrm{L}$ & $\mathrm{L}$ & $\mathrm{L}$ & $\mathrm{U}$ \\
\hline Kaku [13] & $\mathrm{L}$ & $\mathrm{L}$ & $\mathrm{L}$ & $\mathrm{L}$ & $\mathrm{L}$ & $\mathrm{L}$ \\
\hline Kaku [14] & $\mathrm{U}$ & $\mathrm{L}$ & $\mathrm{L}$ & $\mathrm{L}$ & $\mathrm{L}$ & $\mathrm{U}$ \\
\hline Nauck [15] & $\mathrm{L}$ & $\mathrm{U}$ & $\mathrm{L}$ & $\mathrm{L}$ & $\mathrm{L}$ & $\mathrm{U}$ \\
\hline $\operatorname{Pan}[16]$ & $\mathrm{L}$ & $\mathrm{L}$ & $\mathrm{L}$ & $\mathrm{L}$ & $\mathrm{L}$ & $\mathrm{L}$ \\
\hline Pratley [17] & $\mathrm{U}$ & $\mathrm{U}$ & $\mathrm{L}$ & $\mathrm{L}$ & $\mathrm{L}$ & $\mathrm{U}$ \\
\hline Pratley [18] & $\mathrm{L}$ & $\mathrm{U}$ & $\mathrm{L}$ & $\mathrm{L}$ & $\mathrm{L}$ & $\mathrm{U}$ \\
\hline Pratley [19] & $\mathrm{L}$ & $\mathrm{U}$ & $\mathrm{L}$ & $\mathrm{L}$ & $\mathrm{L}$ & $\mathrm{U}$ \\
\hline $\begin{array}{l}\text { Van Raalte } \\
{[25]}\end{array}$ & $\mathrm{H}$ & $\mathrm{U}$ & $\mathrm{L}$ & $\mathrm{L}$ & $\mathrm{L}$ & $\mathrm{H}$ \\
\hline $\begin{array}{l}\text { Rosenstock } \\
{[21]}\end{array}$ & $\mathrm{L}$ & $\mathrm{U}$ & $\mathrm{L}$ & $\mathrm{L}$ & $\mathrm{L}$ & $\mathrm{U}$ \\
\hline $\begin{array}{l}\text { Rosenstock } \\
{[20]}\end{array}$ & $\mathrm{U}$ & $\mathrm{U}$ & $\mathrm{L}$ & $\mathrm{L}$ & $\mathrm{L}$ & $\mathrm{U}$ \\
\hline Seino [22] & $\mathrm{L}$ & $\mathrm{L}$ & $\mathrm{L}$ & $\mathrm{L}$ & $\mathrm{L}$ & $\mathrm{L}$ \\
\hline Seino [23] & $\mathrm{L}$ & $\mathrm{L}$ & $\mathrm{L}$ & $\mathrm{L}$ & $\mathrm{L}$ & $\mathrm{L}$ \\
\hline Seino [24] & $\mathrm{L}$ & $\mathrm{U}$ & $\mathrm{L}$ & $\mathrm{L}$ & $\mathrm{L}$ & $\mathrm{U}$ \\
\hline
\end{tabular}

$U$ unclear, $L$ low, $H$ high

overall PBG changed from baseline was $2.04 \mathrm{mmol} / \mathrm{l} \quad(95 \% \quad$ CI -2.85 to -1.23 ; $\left.P<0.00001 ; I^{2}=81 \%\right)$. Alogliptin proved to be much more effective in the Asian-dominant studies $[-2.42 \mathrm{mmol} / \mathrm{l} \quad(95 \%$ CI -2.99 to $-1.85) ; I^{2}=59 \%$ ] than in non-Asian-dominant studies [- $0.60 \mathrm{mmol} / 1(95 \% \mathrm{CI}-1.60$ to 0.40$)]$ $(P=0.002)$ (Fig. 2d).

\section{Body Weight}

As shown in Fig. 2e, results on the outcome of body weight were available from eight studies [12-14, 18, 20-23]. Although participants taking alogliptin showed a slightly greater weight gain than those on placebo in the context of overall treatment $(\mathrm{WMD}=0.24 \mathrm{~kg}, 95 \%$ CI $\left.0.06-0.41, P=0.007 ; I^{2}=47 \%\right)$, there was no difference $(P=0.47)$ between Asian-dominant studies [0.20 kg (95\% CI 0.00-0.40); $\left.I^{2}=24 \%\right]$ and non-Asian-dominant studies [0.35 kg (95\% CI $\left.0.00-0.70) ; I^{2}=66 \%\right]$ as regards to weight gain.

\section{Safety}

\section{Hypoglycemia}

As shown in Fig. 3c, data on hypoglycemic episodes were retrieved in 12 trials $[11,13-15,17-19,21-25]$. In general, no 
a

\begin{tabular}{|c|c|c|c|c|}
\hline \multirow[t]{2}{*}{ Subgroup } & \multirow{2}{*}{$\begin{array}{c}\mathrm{N} \text { of } \\
\text { studies }\end{array}$} & \multicolumn{2}{|c|}{$\mathrm{N}$ of patients } & \multirow{2}{*}{$\begin{array}{c}\text { HbA1C } \\
\text { WMD, \% } \\
\text { (95\%Cl) }\end{array}$} \\
\hline & & treatment & Control & \\
\hline Asian-dominant studies & 8 & 710 & 707 & $-0.75(-0.84,-0.65)$ \\
\hline Non-Asian-dominant studies & 11 & 1553 & 1242 & $-0.61(-0.68,-0.54)$ \\
\hline
\end{tabular}

\section{$\stackrel{P^{2}}{(\%)}$}

$p$ for difference $=0.02$

b Subgroup

Difference $\begin{array}{cc}\mathrm{N} \text { of } & \mathrm{N} \text { of patients } \\ \text { studies } & \text { treatment Control }\end{array}$

Asian-dominant studies Non-Asian-dominant studies 6 Difference

c Subgroup

$\begin{array}{clll}\text { Asian-dominant studies } & 7 & 614 & 607 \\ \text { Non-Asian-dominant studies } & 12 & 1684 & 1307 \\ \text { Difference } & & & \\ & & & \end{array}$

d Subgroup $\mathrm{N}$ of
studies $\mathrm{N}$ of patients treatment Control

$\begin{array}{cccc}\text { Asian-dominant studies } & 3 & 288 & 290 \\ \text { Non-Asian-dominant studies } & 1 & 112 & 109 \\ \text { Difference } & & & \end{array}$

e $\begin{array}{lcc}\text { Subgroup } & \begin{array}{c}\mathrm{N} \text { of } \\ \text { studies }\end{array} & \mathrm{N} \text { of patients } \\ \text { treatment } & \text { Control }\end{array}$ $\begin{array}{llll}\text { Asian-dominant studies } & 4 & 362 & 354\end{array}$ $\begin{array}{llll}\text { Non-Asian-dominant studies } & 4 & 622 & 456\end{array}$

Difference

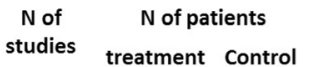
FPG
WMD, $\mathrm{mmol} / \mathrm{I}$ $(95 \% \mathrm{Cl})$

achievement for target goa $\mathrm{HbA} 1 \mathrm{C}<7 \% / 6.9 \%$ $(95 \% \mathrm{Cl})$

$2.88(2.15,3.87)$ $1.93(1.55,2.41)$

$p$ for difference $=0.03$

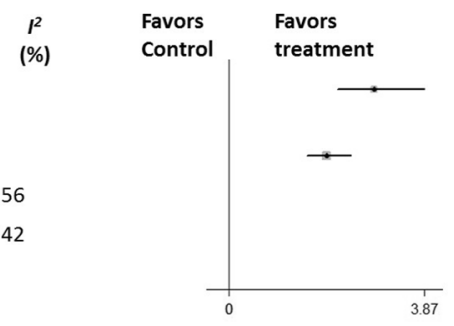

42

$I^{2}$

(\%)

$-1.07(-1.28,-0.85)$

$-1.16(-1.37,-0.96)$

$p$ for difference $=0.53$

44

47

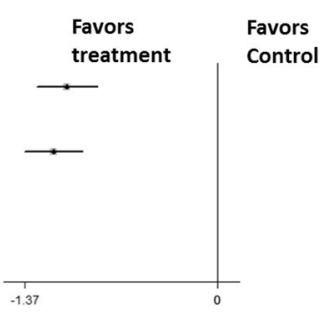

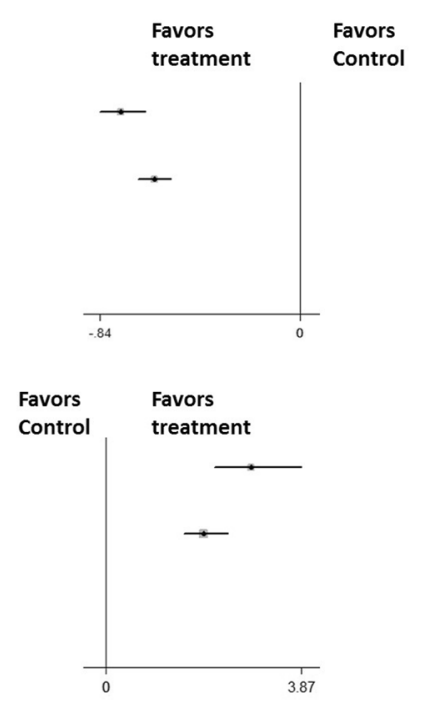

$1^{2}$ WMD, $\mathrm{mmol} / \mathrm{I}$ (95\% Cl)

(\%)

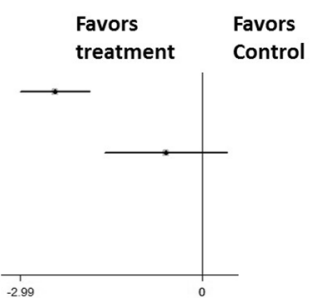

$p$ for difference $=0.002$

$-2.42(-2.99,-1.85)$

$-0.60(-1.60,0.40)$

59 $-$

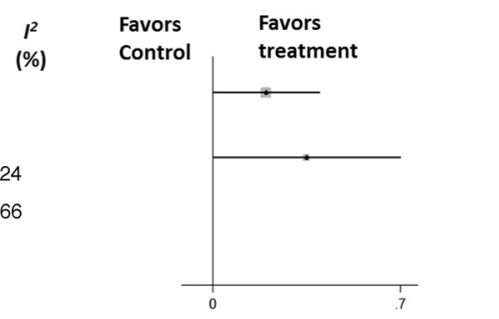

Fig. 2 Difference between Asian-dominant studies and non-Asian-dominant studies in $\mathbf{a} \mathrm{HbAlc}$, $\mathbf{b}$ relative risk of achievement for target goal HbAlc $<7.0 \% / 6.9 \%$, c FPG,

Weight
WMD, kg
$(95 \% \mathrm{Cl})$

$0.20(0.00,0.40)$

$0.35(0.00,0.70)$

$p$ for difference $=0.47$

d PPG, e weight. CI confidence interval, FPG fasting plasma glucose, PPG postprandial plasma glucose, N number, RR risk ratio, WMD weighted mean difference 


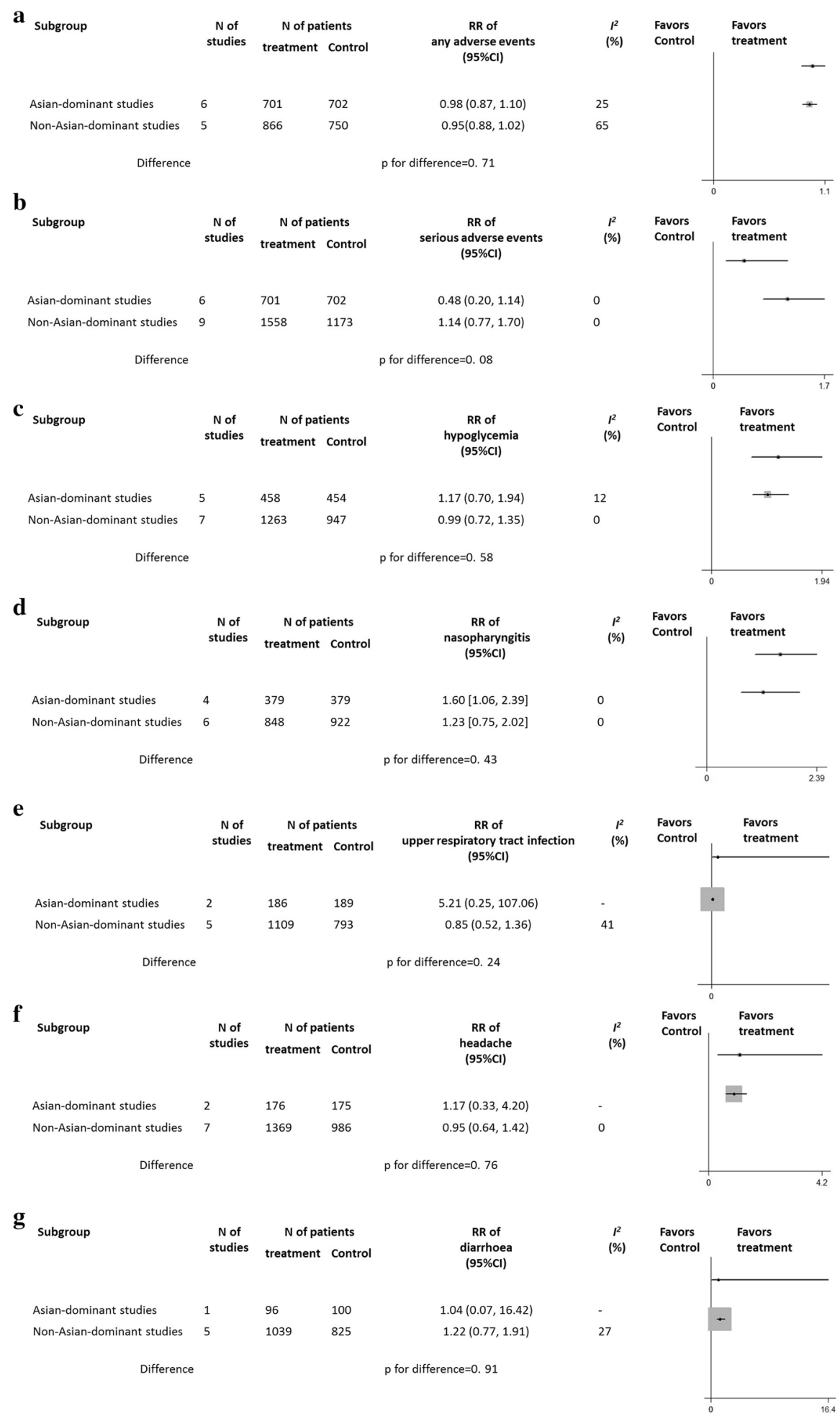

Fig. 3 Difference between Asian-dominant studies and non-Asian-dominant studies in a any adverse events, $\mathbf{b}$ serious adverse events, $\mathbf{c}$ hypoglycemia, $\mathbf{d}$ nasopharyngitis, e upper respiratory tract infection, $\mathbf{f}$ headache, $\mathbf{g}$ diarrhea. $\mathrm{CI}$ confidence interval, $\mathrm{N}$ number, $\mathrm{RR}$ risk ratio 
significant difference $(P=0.58)$ was found between Asian-dominant studies $[\mathrm{RR}=1.17$ (95\% CI 0.70-1.94); $\left.I^{2}=12 \%\right]$ and non-Asiandominant studies $\quad[\mathrm{RR}=0.99 \quad(95 \% \quad \mathrm{CI}$ 0.72-1.35); $\left.I^{2}=0 \%\right]$.

\section{Other Adverse Events}

Figure 3 shows the meta-analysis results for other adverse events. The RR of any adverse events did not indicate statistically significant difference $(P=0.71)$ between Asian-dominant studies [0.98 (95\% CI 0.87-1.10); $I^{2}=25 \%$ ] and non-Asian-dominant studies $[0.95 \quad(95 \%$ CI $\left.0.88-1.02) ; I^{2}=65 \%\right]$. Also, there was no significant difference between two subgroups as regards to serious adverse events $[\mathrm{RR}=0.48$ (95\% CI $0.20-1.14)$ versus $\mathrm{RR}=1.14(95 \% \mathrm{CI}$ 0.77-1.70), $P=0.08$ ]. The most commonly reported adverse events were nasopharyngitis, upper respiratory tract infection, headache, and diarrhea. In addition, there was no significant difference between Asian-dominant studies and non-Asian-dominant studies as regards to nasopharyngitis $[\mathrm{RR}=1.60(95 \% \mathrm{CI} 1.06-2.39)$ versus $\mathrm{RR}=1.23(95 \% \mathrm{CI} 0.75-2.02)(P=0.43)]$, upper respiratory tract infection $[\mathrm{RR}=5.21$ (95\% CI $0.25-107.06)$ versus $0.85 \quad(95 \%$ CI $0.52-1.36) \quad(P=0.24)]$, headache $[\mathrm{RR}=1.17$ $(95 \%$ CI $\quad 0.33-4.20)$ versus $0.95 \quad(95 \%$ CI 0.64-1.42) $(P=0.76)]$, and diarrhea $[\mathrm{RR}=1.04$ $(95 \%$ CI $0.07-16.42)$ versus $1.22 \quad(95 \%$ CI $0.77-1.91)(P=0.91)]$.

\section{DISCUSSION}

This systematic review and meta-analysis involved 15 RCTs focused on alogliptin, a highly selective, potent, and orally available DPP-4 inhibitor [28]. We found that the HbA1clowering efficacy of alogliptin as well as the percentage of patients achieving HbA1c target was greater in Asian-dominant studies than in non-Asian-dominant studies, which implied that alogliptin was more effective in Asian patients with type 2 diabetes than other ethnic groups. Previous meta-analyses, performed by Kim et al., revealed that DPP-4 inhibitors and GLP-1 analogues both exhibit greater glucoselowering efficacy in Asian patients than in non-
Asian patients with type 2 diabetes [4, 5]. Zhang et al. [29], however, found the improvement of DPP-4 inhibitors in HbA1c was similar between Asian and non-Asian patients. The current meta-analysis is the first to identify the efficacy and safety of alogliptin in Asians and nonAsians.

It was believed that BMI value was a main contributor to the differential glycemic effect of DPP-4 inhibitors [4]. The Asian-dominant studies were conducted on lower-BMI groups, whereas non-Asian dominant studies belonged to higher BMI groups. According to the metaregression analysis by Kim et al. [4], when average BMI was less than $30 \mathrm{~kg} / \mathrm{m}^{2}$, the BMI was significantly correlated with HbA1c-lowering efficacy in patients with DPP-4 inhibitors. In a 12-month study, Yagi et al. [30] discovered that DPP-4 inhibitors were more effective in patients with low BMI. Several Japanese studies also found a significant correlation between baseline BMI and HbA1c-lowering effect in patients with sitagliptin treatment [31-33]. The ethnic difference in the glucose-lowering response of alogliptin, therefore, could be largely ascribed to the difference in BMIs.

DPP-4 was proven to be an adipokine, which was substantially expressed in the visceral fat of obese people, and augmented release into circulation [34]. Also, the activity of DPP-4 is higher in obese people [34, 35]. Since both circulating DPP-4 level and activity are increased in obese subjects, the efficacy of DPP-4 inhibitors in non-Asian patients with high BMI should be lower than in Asian patients. So alogliptin was more effective in the Asian group with lower BMI. This may partly explain the difference in effects of alogliptin by ethnicity.

Alogliptin is known to improve $\beta$-cell dysfunction and increase insulin secretion [36]. In a recent study, the authors compared the insulin action between East Asians and Northern Europeans [37]. They revealed that the effect of identical increase of insulin secretion was greater in East Asians than in Northern Europeans, as insulin sensitivity was more pronounced in East Asians than in their Northern European counterparts [37]. This difference may be a contributor to the differential efficacy of alogliptin in different ethnic groups. 
As type 2 diabetes is associated with a strong gene-environmental interaction, several genetic factors were reported to affect the insulin secretion in response to incretin-based therapy. For instance, TCF7L2 could regulate the expression of GIP and GLP-1 receptors in human pancreatic islets [38]. It is also a gene known to be associated with susceptibility of type 2 diabetes [38]. Rs7903146, the allele of the TCF7L2 gene, was reported to confer poor glucose-lowering efficacy of a DPP-4 inhibitor in Europeans [39]. Moreover, in Europeans, the risk allele frequency of rs7903146 is almost tenfold that of East Asians [40]. This may be one of the important factors for the differential efficacy of alogliptin by ethnicity.

The reason for the higher efficacy of alogliptin in the Asian population might also be related to the dietary habit. For instance, Iwasaki and colleagues implied that differing efficacies of DPP-4 inhibitors found among different ethnic groups might be partly a result of differences in fish consumption, since they discovered that a reduction of HbA1c by DPP-4 inhibitors significantly correlates with estimated intake of fish, EPA and DHA, and serum levels of EPA and DHA [41]. In addition, several studies reported that Asian women had a higher mean daily intake of fish than Caucasians $[42,43]$. Thus, dietary habit may influence the efficacy of alogliptin among different ethnicities.

It was thought that because of different body size and BMI value, the pharmacokinetics of alogliptin, which may affect the glucose-lowering efficacy, would differ between Asians and non-Asians; however, no significant difference of clinical pharmacological properties of several DPP-4 inhibitors across different ethnic groups was found [44]. A better clinical response of alogliptin in Asians, therefore, cannot be ascribed to different pharmacokinetics.

In the present meta-analysis, alogliptin reduced PBG more effectively in Asian-dominant studies than non-Asian-dominant studies, whereas the FBG-lowering efficacy across different ethnic groups was similar. Since DPP-4 inhibitors increase activity of GLP-1 and decrease glucagon levels, they are more efficient in treating post-challenge hyperglycemia than fasting hyperglycemia [45]. Interestingly, according to the diabetes epidemiological features of Asia and Europe [46, 47], the prevalence of postprandial hyperglycemia is higher in Asians than in Europeans, and more than 50\% of patients in Asia experienced only isolated post-meal hyperglycemia. These analyses were consistent with our results; however, the included PBG and FBG data in this current meta-analysis were relatively limited. Further long-term RCTs are needed to define the FBGand PBG-lowering efficacy of alogliptin among different ethnic groups.

As is well known, changes in body weight are pivotal aspects for evaluating a hypoglycemic agent. Patients with diabetes often have some comorbidities such as cardiovascular disease and obesity. Weight gain would be a great concern among these patients. Unfortunately, several antidiabetic agents, including sulfonylureas, thiazolidinediones, and insulin, are associated with enhanced risk of weight gain. The weight changes attributed to use of alogliptin in both Asian-dominant studies and non-Asian-dominant studies were minimal, and no significant difference was found between these two subgroups. Most trials reporting weight changes, however, were less than 1 year in duration, so long-term effects on weight are still unclear.

The ADA emphasizes that the prevention of hypoglycemia is crucial in the treatment of T2DM [26]. Hence, before a clinician chooses an antidiabetic agent, the drug's hypoglycemic rate should be considered carefully. The incidences of hypoglycemia and other adverse events, including nasopharyngitis, upper respiratory tract infection, headache, and diarrhea, were all very low in both Asian and non-Asian studies, which suggested that alogliptin is a relatively safe antidiabetic agent.

\section{CONCLUSIONS}

Alogliptin has been shown in 15 RCTs to confer greater glucose-lowering efficacy in Asians than in non-Asians. The difference in the treatment response could be ascribed to different BMI values, insulin action, and dietary habit, as well 
as genetic factors. The present meta-analysis demonstrates that ethnic-specific guidelines are needed for alogliptin, and future studies are required to explore the potential mechanisms.

\section{ACKNOWLEDGEMENTS}

Funding. This work was supported by "the Fundamental Research Funds for the Central Universities" in China (302-413000084).

Authorship. All named authors meet the International Committee of Medical Journal Editors (ICMJE) criteria for authorship for this manuscript, take responsibility for the integrity of the work as a whole, and have given final approval for the version to be published.

Disclosures. Yuli Cai, Tianshu Zeng, Zhongyuan Wen, and Lulu Chen have nothing to disclose.

Compliance with Ethics Guidelines. This article is based on previously conducted studies and does not involve any new studies of human or animal subjects performed by any of the authors.

Data Availability. All data generated or analyzed during this study are included in this published article.

Open Access. This article is distributed under the terms of the Creative Commons Attribution-NonCommercial 4.0 International License (http://creativecommons.org/licenses/ by-nc/4.0/), which permits any noncommercial use, distribution, and reproduction in any medium, provided you give appropriate credit to the original author(s) and the source, provide a link to the Creative Commons license, and indicate if changes were made.

\section{REFERENCES}

1. Sicree RSJ, Zimmet P. Prevalence and projections. In: Gan D, editor. Diabetes atlas, 3rd edn. Brussels: International Diabetes Federation; 2006. pp. 16-104.

2. Kodama K, Tojjar D, Yamada S, Toda K, Patel CJ, Butte AJ. Ethnic differences in the relationship between insulin sensitivity and insulin response: a systematic review and meta-analysis. Diabetes Care. 2013;36:1789-96.

3. Ramachandran A, Ma RC, Snehalatha C. Diabetes in Asia. Lancet. 2010;375:408-18.

4. Kim YG, Hahn S, Oh TJ, Kwak SH, Park KS, Cho YM. Differences in the glucose-lowering efficacy of dipeptidyl peptidase- 4 inhibitors between Asians and non-Asians: a systematic review and metaanalysis. Diabetologia. 2013;56:696-708.

5. Kim YG, Hahn S, Oh TJ, Park KS, Cho YM. Differences in the HbA1c-lowering efficacy of glucagonlike peptide- 1 analogues between Asians and nonAsians: a systematic review and meta-analysis. Diabetes Obes Metab. 2014;16:900-9.

6. Park H, Park C, Kim Y, Rascati KL. Efficacy and safety of dipeptidyl peptidase-4 inhibitors in type 2 diabetes: meta-analysis. Ann Pharmacother. 2012;46:1453-69.

7. Cai Y, Zeng T, Chen L. Association of adiponectin polymorphisms with the risk of diabetic nephropathy in type 2 diabetes: a meta-analysis. J Diabetes. 2015;7:31-40.

8. Higgins J, Altman D, Stern J. Assessing risk of bias in included studies. In: Higgins J, Green S, editors. Cochrane handbook for systematic reviews of interventions. The Cochrane Collaboration; 2008. pp. 187-241.

9. DerSimonian R, Laird N. Meta-analysis in clinical trials. Control Clin Trials. 1986;7:177-88.

10. Mantel N, Haenszel W. Statistical aspects of the analysis of data from retrospective studies of disease. J Natl Cancer Inst. 1959;22:719-48.

11. DeFronzo RA, Burant CF, Fleck P, Wilson C, Mekki Q, Pratley RE. Efficacy and tolerability of the DPP-4 inhibitor alogliptin combined with pioglitazone, in 
metformin-treated patients with type 2 diabetes. J Clin Endocrinol Metab. 2012;97:1615-22.

12. DeFronzo RA, Fleck PR, Wilson CA, Mekki Q, Alogliptin Study 010 Group. Efficacy and safety of the dipeptidyl peptidase-4 inhibitor alogliptin in patients with type 2 diabetes and inadequate glycemic control: a randomized, double-blind, placebo-controlled study. Diabetes Care. 2008;31:2315-7.

13. Kaku K, Itayasu T, Hiroi S, Hirayama M, Seino Y. Efficacy and safety of alogliptin added to pioglitazone in Japanese patients with type 2 diabetes: a randomized, double-blind, placebo-controlled trial with an open-label long-term extension study. Diabetes Obes Metab. 2011;13:1028-35.

14. Kaku K, Mori M, Kanoo T, Katou M, Seino Y. Efficacy and safety of alogliptin added to insulin in Japanese patients with type 2 diabetes: a randomized, double-blind, 12-week, placebo-controlled trial followed by an open-label, long-term extension phase. Expert Opin Pharmacother. 2014;15:2121-30.

15. Nauck MA, Ellis GC, Fleck PR, Wilson CA, Mekki Q, Alogliptin Study 008 Group. Efficacy and safety of adding the dipeptidyl peptidase- 4 inhibitor alogliptin to metformin therapy in patients with type 2 diabetes inadequately controlled with metformin monotherapy: a multicentre, randomised, doubleblind, placebo-controlled study. Int J Clin Pract. 2009;63:46-55.

16. Pan C, Han P, Ji Q, et al. Efficacy and safety of alogliptin in patients with type 2 diabetes mellitus: a multicentre randomized double-blind placebocontrolled Phase 3 study in mainland China, Taiwan, and Hong Kong. J Diabetes. 2017;9:386-95.

17. Pratley RE, Fleck P, Wilson C. Efficacy and safety of initial combination therapy with alogliptin plus metformin versus either as monotherapy in drugnaive patients with type 2 diabetes: a randomized, double-blind, 6-month study. Diabetes Obes Metab. 2014;16:613-21.

18. Pratley RE, Kipnes MS, Fleck PR, Wilson C, Mekki Q, Alogliptin Study 007 Group. Efficacy and safety of the dipeptidyl peptidase- 4 inhibitor alogliptin in patients with type 2 diabetes inadequately controlled by glyburide monotherapy. Diabetes Obes Metab. 2008;11:167-76.

19. Pratley RE, Reusch JE, Fleck PR, Wilson CA, Mekki Q, Alogliptin Study 009 Group. Efficacy and safety of the dipeptidyl peptidase- 4 inhibitor alogliptin added to pioglitazone in patients with type 2 diabetes: a randomized, double-blind, placebo-controlled study. Curr Med Res Opin. 2009;25:2361-71.
20. Rosenstock J, Inzucchi SE, Seufert J, Fleck PR, Wilson CA, Mekki Q. Initial combination therapy with alogliptin and pioglitazone in drug-naive patients with type 2 diabetes. Diabetes Care. 2010;33:2406-8.

21. Rosenstock J, Rendell MS, Gross JL, Fleck PR, Wilson CA, Mekki Q. Alogliptin added to insulin therapy in patients with type 2 diabetes reduces $\mathrm{HbA}(1 \mathrm{C})$ without causing weight gain or increased hypoglycaemia. Diabetes Obes Metab. 2009; 11:1145-52.

22. Seino $Y$, Fujita T, Hiroi S, Hirayama M, Kaku K. Alogliptin plus voglibose in Japanese patients with type 2 diabetes: a randomized, double-blind, placebo-controlled trial with an open-label, long-term extension. Curr Med Res Opin. 2011;27(Suppl 3):21-9.

23. Seino Y, Fujita T, Hiroi S, Hirayama M, Kaku K. Efficacy and safety of alogliptin in Japanese patients with type 2 diabetes mellitus: a randomized, double-blind, dose-ranging comparison with placebo, followed by a long-term extension study. Curr Med Res Opin. 2011;27:1781-92.

24. Seino Y, Miyata Y, Hiroi S, Hirayama M, Kaku K. Efficacy and safety of alogliptin added to metformin in Japanese patients with type 2 diabetes: a randomized, double-blind, placebo-controlled trial with an open-label, long-term extension study. Diabetes Obes Metab. 2012;14:927-36.

25. Van Raalte DH, van Genugten RE, Eliasson B, et al. The effect of alogliptin and pioglitazone combination therapy on various aspects of beta-cell function in patients with recent-onset type 2 diabetes. Eur J Endocrinol. 2014;170:565-74.

26. American Diabetes Association. Standards of medical care in diabetes-2017. Diabetes Care. 2017;40:S1-135.

27. Society JD. Evidence-based practice guideline for the treatment of diabetes in Japan. 2nd ed. Tokyo: Nankodo; 2007.

28. Pratley RE. Alogliptin: a new, highly selective dipeptidyl peptidase- 4 inhibitor for the treatment of type 2 diabetes. Expert Opin Pharmacother. 2009;10:503-12.

29. Zhang X, Brooks B, Molyneaux L, et al. Dipeptidyl peptidase- 4 inhibitors as a third-line oral antihyperglycaemic agent in patients with type 2 diabetes mellitus: the impact of ethnicity. Int J Endocrinol. 2014;2014:354040.

30. Yagi S, Aihara K, Akaike M, et al. Predictive factors for efficacy of dipeptidyl peptidase- 4 inhibitors in 
patients with type 2 diabetes mellitus. Diabetes Metab J. 2015;39:342-7.

31. Aso Y, Ozeki N, Terasawa T, et al. Serum level of soluble CD26/dipeptidyl peptidase-4 (DPP-4) predicts the response to sitagliptin, a DPP-4 inhibitor, in patients with type 2 diabetes controlled inadequately by metformin and/or sulfonylurea. Transl Res. 2012;159:25-31.

32. Maeda H, Kubota A, Tanaka Y, Terauchi Y, Matsuba I, ASSET-K Study group. The safety, efficacy and predictors for HbA1c reduction of sitagliptin in the treatment of Japanese type 2 diabetes. Diabetes Res Clin Pract. 2012;95:e20-2.

33. Nomiyama T, Akehi Y, Takenoshita H, et al. Contributing factors related to efficacy of the dipeptidyl peptidase-4 inhibitor sitagliptin in Japanese patients with type 2 diabetes. Diabetes Res Clin Pract. 2012;95:e27-8.

34. Lamers D, Famulla S, Wronkowitz N, et al. Dipeptidyl peptidase 4 is a novel adipokine potentially linking obesity to the metabolic syndrome. Diabetes. 2011;60:1917-25.

35. Kirino Y, Sei M, Kawazoe K, Minakuchi K, Sato Y. Plasma dipeptidyl peptidase 4 activity correlates with body mass index and the plasma adiponectin concentration in healthy young people. Endocr J. 2012;59:949-53.

36. Drucker DJ, Nauck MA. The incretin system: glucagon-like peptide- 1 receptor agonists and dipeptidyl peptidase- 4 inhibitors in type 2 diabetes. Lancet. 2006;368:1696-705.

37. Moller JB, Pedersen M, Tanaka H, et al. Body composition is the main determinant for the difference in type 2 diabetes pathophysiology between Japanese and Caucasians. Diabetes Care. 2014;37:796-804.

38. Shu L, Matveyenko AV, Kerr-Conte J, Cho JH, McIntosh CH, Maedler K. Decreased TCF7L2 protein levels in type 2 diabetes mellitus correlate with downregulation of GIP- and GLP-1 receptors and impaired beta-cell function. Hum Mol Genet. 2009;18:2388-99.
39. Zimdahl H, Ittrich C, Graefe-Mody U, et al. Influence of TCF7L2 gene variants on the therapeutic response to the dipeptidylpeptidase- 4 inhibitor linagliptin. Diabetologia. 2014;57:1869-75.

40. Yasuda K, Miyake K, Horikawa Y, et al. Variants in KCNQ1 are associated with susceptibility to type 2 diabetes mellitus. Nat Genet. 2008;40:1092-7.

41. Iwasaki M, Hoshian F, Tsuji T, et al. Predicting efficacy of dipeptidyl peptidase- 4 inhibitors in patients with type 2 diabetes: association of glycated hemoglobin reduction with serum eicosapentaenoic acid and docosahexaenoic acid levels. J Diabetes Investig. 2012;3:464-7.

42. Maskarinec G, Takata Y, Kaaks R. The relation between nutritional factors and insulin-like growth factor-I in premenopausal women of different ethnicity. Eur J Nutr. 2005;44:105-13.

43. Tam CY, Hislop G, Hanley AJ, Minkin S, Boyd NF, Martin LJ. Food, beverage, and macronutrient intakes in postmenopausal Caucasian and Chinese-Canadian women. Nutr Cancer. 2011;63:687-98.

44. Vilsboll T, Krarup T, Sonne J, et al. Incretin secretion in relation to meal size and body weight in healthy subjects and people with type 1 and type 2 diabetes mellitus. J Clin Endocrinol Metab. 2003;88:2706-13.

45. DeFronzo RA, Okerson T, Viswanathan P, Guan X, Holcombe JH, MacConell L. Effects of exenatide versus sitagliptin on postprandial glucose, insulin and glucagon secretion, gastric emptying, and caloric intake: a randomized, cross-over study. Curr Med Res Opin. 2008;24:2943-52.

46. Kahn SE, Hull RL, Utzschneider KM. Mechanisms linking obesity to insulin resistance and type 2 diabetes. Nature. 2006;444:840-6.

47. Jensen CC, Cnop M, Hull RL, Fujimoto WY, Kahn SE, American Diabetes Association GSG. Beta-cell function is a major contributor to oral glucose tolerance in high-risk relatives of four ethnic groups in the US. Diabetes. 2002;51:2170-8. 